\title{
Life Experiences Throughout the Lifespan: What Do People Say (or Not) About Them?
}

\author{
Vanessa Azevedo $^{1}$ (i) $\cdot$ Carla Martins $^{1} \cdot$ Ângela Maia $^{1}$ \\ ๑) Springer Science+Business Media, LLC, part of Springer Nature 2017
}

\begin{abstract}
Life experiences have been a topic of interest for researchers and clinicians for decades. Current knowledge is rooted in two distinct approaches, i.e., personality psychology and psychosomatics. Whereas the first is interested in ordinary life stories of nonclinical individuals, based on a more qualitative, in-depth, and person-driven approach, psychosomatics stresses negative events, mainly in clinical samples, and presents a more quantitative, general, and construct-driven approach. Consequently, available evidence is dispersed and unrelated and many basic questions remain unanswered. This study aimed to explore occurrence, developmental stage, valence, and impact of life experiences and to analyze critical answering patterns (i.e., "I don't remember," missingness). Through a cross-sectional retrospective design, 394 adults from the community answered the Lifetime Experiences Scale, which covers 75 life experiences organized in eight domains (i.e., school, job, health, leisure, living conditions, adverse experiences, achievements, and people and relationships). Occurrence of life experiences varied greatly, and the mean number of experiences reported was approximately 30 . Regarding developmental stage, most experiences were reported in just one stage-mainly adulthood—however, some could be considered chronic. Globally, life experiences tended to be clearly rated as positive or as negative; additionally, assessed experiences were mainly appraised as positive. Moreover, participants presented their experiences as significant, rating them as high impact. Overall, critical answering patterns were not very expressive: "I don't remember" and missing answers were below 2 and 5\%, respectively, in the majority of experiences. These findings offer several important new insights, suggesting that life experiences are mainly an idiosyncratic topic.
\end{abstract}

Keywords Life events $\cdot$ Retrospective recall $\cdot$ Self-report $\cdot$ Personal meanings $\cdot$ Lifespan

\section{Introduction}

Although life experiences seem to be an implicit ever-present scientific topic, the end of the Second World War established a major turning point, definitively placing it on clinicians and researchers' agenda (Paykel 2001). Since then, this topic has been rooted in two distinct approaches, namely personality psychology and psychosomatics, which present their own strategies to conceptualize and assess it. More specifically, personality psychology seems to be particularly interested in life stories of nonclinical subjects, inspired by the pioneering work of Henry A. Murray (1893-1988) at the Harvard Psychological Clinic, who revolutionized psychology focusing

Vanessa Azevedo

vazevedo@psi.uminho.pt

1 School of Psychology, University of Minho, Campus de Gualtar, 4710-057 Gualtar, Braga, Portugal on new variables: "Time, story, the person. Human beings are time-binding, story-telling creators, whose lives themselves are situated in time, as time-binding narratives-past, present, future" (McAdams 2001, p. 690). Concomitantly, psychosomatics attempts to explain the etiology and course of mental, physical or psychosomatic problems through life events (Paykel 2001); this line of research focuses primarily on clinical cases and stresses negative events. Moreover, whereas personality psychology favors more qualitative, indepth, person-driven approaches, which resulted in a type of stagnation for years and only now "is enjoying something of a renaissance" (McAdams 2001, p. 692); psychosomatics applies a more quantitative, general, and construct-driven approach and has become a flourishing topic. A detailed comparison between the two approaches is beyond the scope of this paper; however, these general ideas are crucial to understand the current state of art. 
In a previous work (Azevedo et al. 2017), we defined life experience as a set of events (I was born...), conditions (I live/lived...), and perceptions (I feel/felt...) that occur (or not) during a lifetime. According to this definition, life experiences include, but are not limited to, life events. Additionally, life experiences are not limited to self; instead they also embrace the individual's environment, other relevant people and the interactions among them. The focus of life experiences is personal and it includes two types of features: an objective (involving factual data) and a subjective (involving meanings). Consequently, although the occurrence of life events, conditions, and perceptions can be shared, it is unlikely that two people experience them in exactly the same way and even the same individual can change the subjective features throughout the lifespan.

Briefly, four trends characterize current knowledge of life experiences. First, despite the assertions about the relevance of positive experiences (e.g., Scully et al. 2000; Zimmerman 1983), this field of research has replicated a general trend in psychology toward the negative (e.g., Baumeister et al. 2001; Suh et al. 1996). Indeed, few of the available measures assessed positive experiences-the Life Experiences Survey by Sarason et al. (1978) is one of the exceptions-and few studies addressed both valences (Overbeek et al. 2010). After reviewing available data, Baumeister et al. (2001, p. 326) concluded that "developmental and clinical observations likewise suggest that single bad events are far stronger than even the strongest good one"; however, this conclusion can be biased by an obvious trend: there are many more results about negative experiences than positive ones and many possible reasons for this asymmetry (e.g., disinterest, gray data). Second, reference periods are typically restricted to childhood/adolescence or adulthood experiences. Therefore, some authors (e.g., Davis et al. 1999; Dohrenwend 2006) argued about the relevance of adopting a lifespan perspective, instead of short limited reference periods. Third, most studies relied on cross-sectional retrospective design ${ }^{1}$ due to its advantages, such as being less expensive, allowing more rapid data collection, and being less demanding for both researchers and participants (e.g., Beckett et al. 2001; Hardt and Rutter 2004; Kendall-Tackett and Becker-Blease 2004; Shaffer et al. 2008) and collected data based on life experiences lists through self-report or

\footnotetext{
1 According to Grotpeter (2008, p. 120), cross-sectional research design is a "research that uses a cross-sectional design, but by use of retrospective recall methods, gathers longitudinal data. These data are designed to represent attitudes, behavior, and events in the respondents' lives across time, despite the fact they are collected at a single point in time."
}

structured interviews (e.g., Davis et al. 1999; Dohrenwend 2006; Hobson and Delunas 2001; Paykel 2001). Fourth, most studies still focused on life experiences and health, presenting correlational or explanatory purposes. Consequently, a descriptive in-depth approach regarding life experiences is not a central aim, being dismissed by most research. Moreover, data about occurrence, followed by probes (e.g., people involved, frequency), are the most common way of reporting life experiences, whereas data about meanings are scarcer; as a result, available information is mainly descriptive and less comprehensive.

Attending to this state of the art, it is not difficult to understand why, at this point, some basic questions remain unanswered. What are the most common and the most infrequent experiences throughout the lifespan? When do they occur: in childhood, adolescence, or adulthood? Do they tend to be limited to certain development stages or tend to remain across stages? What are the valences-positive, negative or neutral—of different life experiences? How do people rate the impacts of different life experiences? Although common sense would probably provide easy answers to these questions, few empirical studies have addressed them (some are presented below), and to the best of our knowledge no previous study included such a comprehensive analysis, which could be useful and informative for both researchers and clinicians.

A remarkable study about childhood abuse and neglect is the CDC-Kaiser Permanente Adverse Childhood Experiences (ACE) Study, conducted by the Centers for Disease Control and Prevention (CDC) and the Kaiser Permanente health maintenance organization. Between 1995 and 1997, the ACE Study assessed the childhood experiences of 17,337 participants through a mailed questionnaire. According to the available data on its website (2016), of the participants, $46 \%$ were male, $46.4 \%$ were aged 60 or older, $19.9 \%$ were aged 50-59, and 5.3\% were aged $19-29$. Overall, $36.1 \%$ did not report any ACE, and $12.5 \%$ reported four or more ACEs. In addition to counting their numbers, ACEs can be grouped into three categories: abuse, household challenges, and neglect. The prevalence of physical abuse was $28.3 \%$; sexual abuse was reported by $20.7 \%$ of the participants, and emotional abuse by $10.6 \%$. Additionally, emotional and physical neglect were reported, respectively, by 14.8 and $9.9 \%$ of the participants. Concerning household challenges, the most prevalent were household substance abuse (26.9\%), parental separation or divorce (23.3\%), and household mental illness (19.4\%). Moreover, $12.7 \%$ of the participants reported that their mother was treated violently, and $4.7 \%$ reported an incarcerated household member. Because the ACE Study is introduced as "one of the largest investigations of childhood abuse and neglect and later-life health and well-being," its main focus on relationship life experiences and their longterm impact is understandable. Indeed, researchers collected 
data on not only mental and physical health (i.e., depression, ischemic disease, sexually transmitted diseases, and suicide attempts) but also other domains, such as finances and academic achievement.

The Social Readjustment Rating Scale (SRRS), by Holmes and Rahe (1967), was a pioneering measure (e.g., Paykel 2001; Zimmerman 1983). Since it remains one of the most widely used measures for both research and clinical purposes, recently Scully et al. (2000) analyzed its main criticisms and re-examined the original findings, in a two-phase study, presenting an updated analysis of the main results. The initial analyses were based on responses from 200 adults; their mean age was $41.48(S D=15.96)$, and $42 \%$ were male. Through telephone interviews, the participants were asked to rate the relative degree of readjustment necessary for each life event, considering that an arbitrary value of 500 was associated with marriage. The comparison of the recent data with those from the original publication concluded that the two experiences that required the most adjustment, i.e., death of a spouse and divorce, were stable. Additionally, there was a general trend of decreasing weight among the 43 experiences assessed, except in ten items (i.e., personal injury or illness, change in health of family member, change in financial state, foreclosure of mortgage or loan, change in living conditions, change in work hours and conditions, change in social activities, change in sleep habits, change in number of family get-togethers, and minor violations of the law). The second phase of the study assessed, through selfreport, 188 participants from a convenience sample, which included college students, business executives, and stress seminar participants; the mean age was $37.05(S D=9.09)$, and $56 \%$ were male. Although the participants were asked about the occurrence of life events, assessing two reference periods (i.e., in the past 12 months and during one's lifetime), these descriptive data were not present. Instead, the authors reported commonality analyses to predict stressrelated symptoms, based on raters' judgments about the (un)desirability of the experiences (for instance, marriage and vacation were rated as desirable, divorce and death of a close family member as undesirable, and changes in working conditions or in living conditions as neutral).

Schroots and Assink (2005) also provided some interesting evidence about life experiences, presenting a different point of view-both conceptually (i.e., a phenomenoncentered approach) and methodologically (i.e., the Life-Line Interview Method and metaphors). The authors interviewed 98 participants (48\% male), divided into three age groups, i.e., early adulthood, from 18 to 30 years old; middle adulthood, from 31 to 55; and later adulthood, from 56 to 84 , to identify portraits of life, which are compressions of patterns of events conveniently arranged in tables serving the composition of simplified life stories. Briefly, participants are shown a board with a blank piece of paper on which a grid is printed. After the procedures are explained and exemplified, participants are asked to draw their life-line from birth to calendar-age, and then they are

asked to label each peak (positive affect) and each dip (negative affect) by chronological age and to tell briefly what happened at a certain moment or during an indicated period. At the same time iter [interviewer] makes a verbatim report of what itee [interviewee] sees as the most important events in his/her life (p. 185).

In Schroots and Assink's study, data analysis was based on life events as the basic unit, organized in nine pre-specified categories (i.e., relationships, school, work, health, home, birth, death, growth, and other) and by decade; the results were presented based on the number of events per (sub)category, and the most frequent categories by decade were selected. Overall, the participants reported a mean of 4.96 past experiences $(S D=2.46)$; this value was significantly affected by age group (young $=3.76$ vs. middle $=5.06$ vs. old $=6.24$ ). The modal category was relationships, whereas birth and other represented the least frequent; there were gender differences (males reported more events about work vs. females reported more events about health and birth) and age differences (i.e., young participants reported more events included in school and growth and fewer in work and health). Moreover, experiences such as births (i.e., child, grandchild), individual growth, leaving home, commitment, and beginning and changing work were evaluated as positive; in contrast, work problems, health of others, growth problems, deaths (i.e., parents, family), and ending relationships were rated as negative. In sum, the authors concluded that prototypical life stories or portraits are "a global picture of life in which childhood is characterized by school and home, young adulthood by relations, middle adulthood by work, and late adulthood by health and death" (p. 188), including both positive and negative experiences. Despite the merits and useful findings provided by this work, a limitation should be stressed: due to the criterion applied, i.e., high frequency, some relevant but unusual or rare experiences were probably dismissed.

At this point, it is clear that we had scarce and sparse knowledge of life experiences and their personal meanings, it being difficult to answer the question of what people say about their life experiences. However, even more doubts remain regarding potential strategies to not speak about life experiences. Indeed, missingness is a concern among researchers (Graham 2009), usually associated with threats to both the internal and external validity of research (Foster and Krivelyova 2008) and challenges associated with data analysis (Schafer and Graham 2002); unfortunately, this scenario also applied to life experiences research. The concept of missingness included two distinct phenomena, i.e., unit nonresponse 
["occurs when the entire data collection procedure fails (because the sampled person is not at home, refuses to participate, etc.)"] and item nonresponse ["means that partial data are available (i.e., the person participates but does not respond to certain individual items)"], according to the definitions provided by these authors (p. 149). Therefore, longitudinal studies tend to be particularly sensitive to unit nonresponse (including dropout), whereas item nonresponse affects all designs. Despite the relevance and the recommendations of the American Psychological Association (e.g., APA Publications and Communications Board-Working Group on Journal Article Reporting 2008), missingness is typically not the main focus of inquiry (Schafer and Graham 2002) nor properly reported (e.g., Enders and Gottschall 2011); instead, it seems to be an implicit topic useful for the discussion (as an explanation or as a limitation) that demands further attention. Although there is a common opinion that "sensitive questions probably yield more missing data then other questions" (Tourangeau et al. 2009, p. 260), to our best knowledge, no previous research on life experiences clearly addressed item nonresponse missingness, exploring its frequency and patterns. In the absence of such basic knowledge, it would be difficult (if not impossible) to address more complex issues regarding missing data theory.

To overcome current limitations, allying features from both personality psychology and psychosomatics, we designed a descriptive study that presents several novelties: It is rooted in a well-defined concept of life experiences, covering a wide range of domains. Additionally, it is rooted in a lifespan perspective, allowing participants to specify when the experiences occurred (i.e., childhood, adolescence or adulthood). Moreover, instead of establishing a priori the valence and impact, these meanings were directly collected from participants. Lastly, it explores a common but highly neglected concern in this field of research, i.e., missingness and its patterns. In sum, through a cross-sectional retrospective design, based on a community sample, this study aimed to identify the occurrence of a variety of life experiences; establish those that are more and less frequent; link the occurrence of life experiences to specific development stages, namely childhood, adolescence, and adulthood; explore how participants experienced them, more specifically regarding their valence and impact; identify which life experiences were more prone to critical answering patterns (i.e., "I don't remember," missings); and examine missingness, namely its patterns, the associated features (e.g., valence, developmental stage), and group characteristics (e.g., gender, education).

\section{Method}

\section{Participants}

Participants from the community aged 18 or above were recruited to enroll in a study about positive and negative life experiences. An inability to read or understand Portuguese was the single exclusion criterion used to select participants; additionally, due to our aims, any exclusion was made based on the number of missings.

This study consisted of 394 individuals, mainly female $(76.4 \%)$, with a mean age of 35.94 years $(S D=19.08$, range 18-92). Most were single (56.0\%); $32.8 \%$ were married or cohabiting; $6.9 \%$ were widowed, and $4.3 \%$ were separated or divorced. Regarding education, $44.4 \%$ of the participants had finished secondary education or taken a professional course; $38.4 \%$ had finished a graduate or undergraduate program; $11.7 \%$ had finished the first, second or third cycle of basic education; and 5.6\% had never attended school. When the data were collected, $46.2 \%$ of the participants were employed; $35.3 \%$ were students; $10.7 \%$ were retired; $6.1 \%$ were unemployed, and $1.8 \%$ reported other labor force status.

\section{Measures and Procedures}

A sociodemographic questionnaire, including questions about age, gender, marital status, education, and employment status, was used to characterize the participants. Data on life experiences were collected using the Lifetime Experiences Scale (Azevedo et al. 2017), a measure that covers 75 life experiences organized in eight domains, i.e., school, job, health, leisure, living conditions, adverse experiences, achievements, and people and relationships. For each item, except in the filter items, the participants were asked about occurrence-yes vs. no vs. I don't remember, the developmental stage-childhood, adolescence, and adulthood, valence-negative vs. neutral vs. positive, and impact-using a five-point Likert scale ranging from 0 (not at all) to 4 (absolutely). When participants answered positively on occurrence, they could select one or more than one developmental stage and rate valence and impact for each selection.

After ethical approval from the Institutional Review Board and the National Commission for Data Protection, a multi-source recruitment was conducted (e.g., schools, institutions, retirement homes) to maximize the sociodemographic heterogeneity of the sample. Individuals were personally invited to participate in a study about positive and negative life experiences and were fully briefed on the study's terms and conditions (such as aims, procedures, 
potential risks and benefits, confidentiality/anonymity, and refusal or withdrawal). For those who agreed to take part, written informed consent was obtained before data collection. Initially, the participants answered the sociodemographic questionnaire and then LIFES; the package took 20-30 min to complete. Data were collected individually using self-reports (in $90.4 \%$ of the cases) or through interviews (9.6\%), between January 2013 and April 2015.

\section{Statistical Analysis}

The data were analyzed through the software IBM Statistical Package for Social Sciences (IBM SPSS for Windows, version 22.0, IBM Corp, Armonk, NY, USA). According to our aims, univariate descriptive statistics were computed for occurrence, developmental stage, chronicity, valence, and impact. All life experiences were analyzed for occurrence; however, seven items were excluded from further analyses for one of two reasons (i.e., absence of responses or filter item). To evaluate chronicity, a new variable was created based in counts of occurrences on the three developmental stages, resulting in three categories (one vs. two vs. three developmental stages). Since participants could rate separately the valence and impact for the three developmental stages, global scores were computed through sums. Additionally, the original ratings for impact were recoded into three categories ( 0 and $1=$ low impact; $2=$ medium impact; 3 and $4=$ high impact). The classification of life experiences regarding their developmental stage, chronicity, valence, and impact was based on a majority criterion, which means that at least $51 \%$ of the participants reported or rated a specific category; when a trend was not clear, items were classified as undefined.

To explore missingness, a missing analysis based on the occurrence of life experiences was also performed, using descriptive statistics and pattern analysis through multiple imputation. More specifically, the percentage of missing variables, cases, and individuals was computed for the total sample and for different groups (gender, age, education, marital status, and labor force status).

\section{Results}

\section{Occurrence}

The number of experiences reported ranged from 0 to 48 $(M=29.71$ experiences, $S D=7.09)$. According to Table 1 , the frequency of occurrence of each life experience ranged from 0 to $99 \%$. The most reported experiences were as follows: I felt loved and cherished, I felt that someone cared about me and about my well-being, and I experienced pleasure when taking care of my child. In contrast, the experiences I was arrested, I was expelled from school, and I was involved in a crime were the least reported by our participants. An analysis by domain revealed a global trend to include both high- and low-frequency experiences, with two exceptions, namely adverse experiences (which covered uncommon experiences) and accomplishments (which covered frequent experiences).

\section{Developmental Stage and Chronicity}

Only two items-I changed schools at the same academic level and I had any unwanted sexual contact -were selected by most participants only in childhood. Four items-I failed a school year, I abandoned school, I was expelled from school, and I was involved in a crime-were limited to adolescence by the majority of the participants. Moreover, 30 life experiences, associated mainly with job, health, living conditions, and intimate relationship and children issues, were restricted to adulthood. Although all the items could be reported in more than one developmental stage, most life experiences, from all the domains-with some exceptions in leisure and parents' relationship — tended to be reported as limited to only one stage. Regarding experiences that occurred across different developmental stages, six life experiences were reported in both childhood and adolescence (including physical and psychological abuse); nine life experiences occurred in both adolescence and adulthood (specially involving accomplishments and people and relationships), and 15 were reported in all the developmental stages (usually experiences associated with leisure, parents' relationship, and care and affection).

\section{Valence}

As displayed in Table 1, life experiences tended to be clearly rated as positive or negative by most participants, except in the items I was admitted to a hospital, I got divorced or separated, and I felt I did not know what to do regarding my child. Overall, 37 items were rated as positive by most participants, whereas 23 life experiences were rated mainly as negative. The experiences I accomplished a project/fulfilled a dream that I really wanted, I felt I was a good mother, and I experienced pleasure when taking care of my child were the experiences highly rated as positive. Inversely, experiences rated as negative by all the participants were I lost my house or my belongings, I was forced to leave my child, and my child had a serious disease or had severe disability.

\section{Impact}

Only three items were rated by the majority of the participants as having little impact (i.e., I was involved in a fire, I was expelled from school, and I was involved in a crime), 


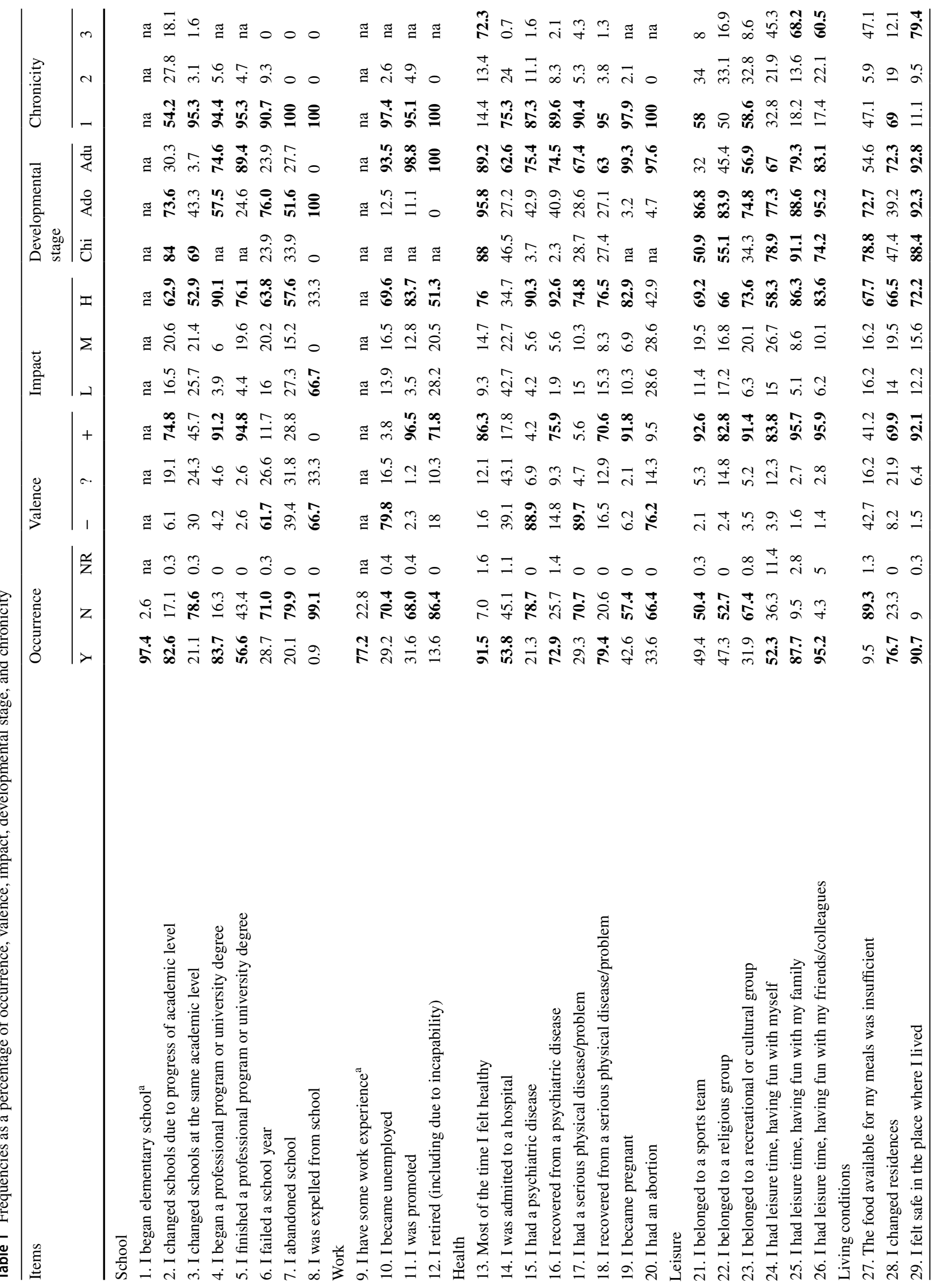




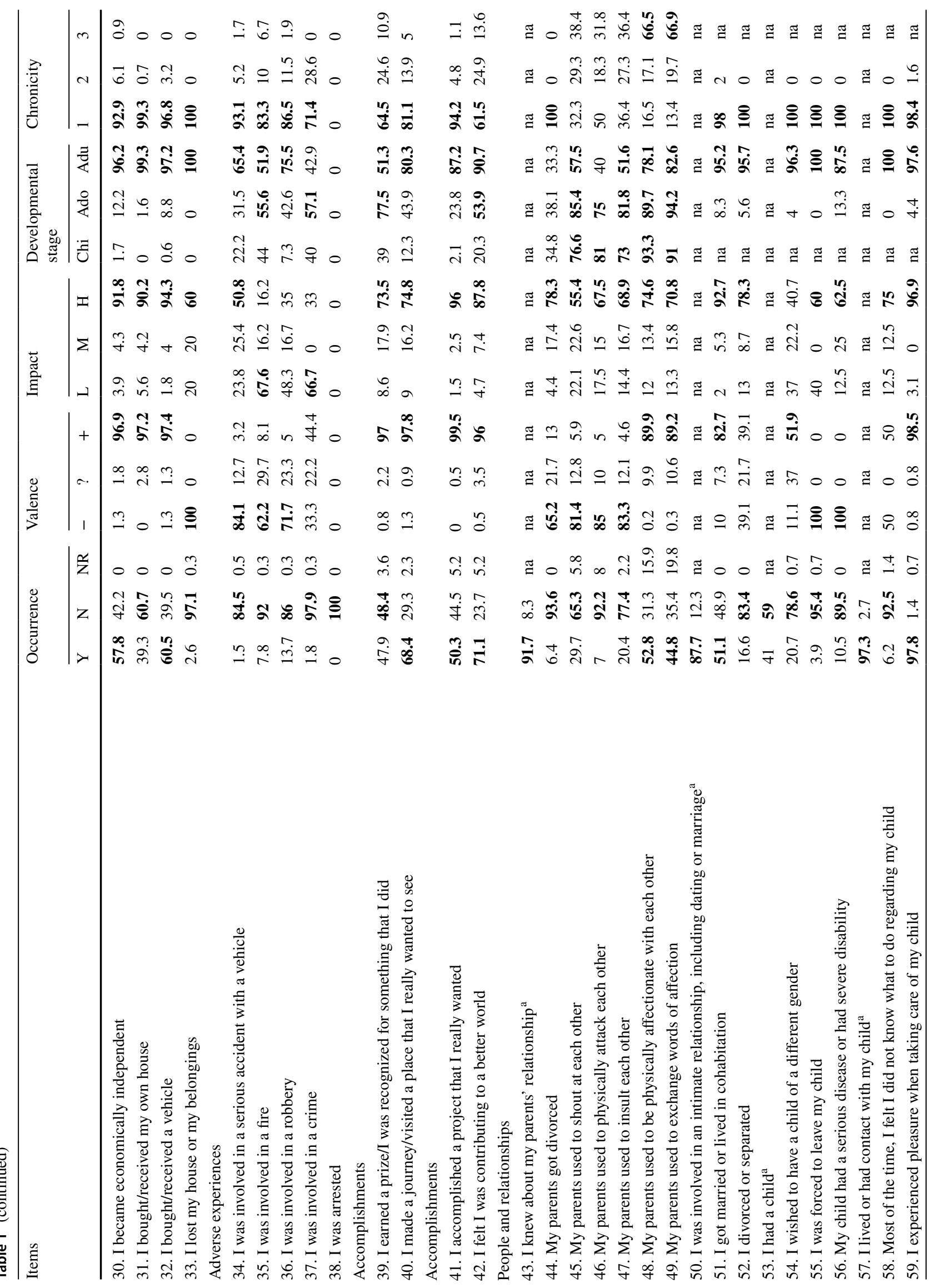




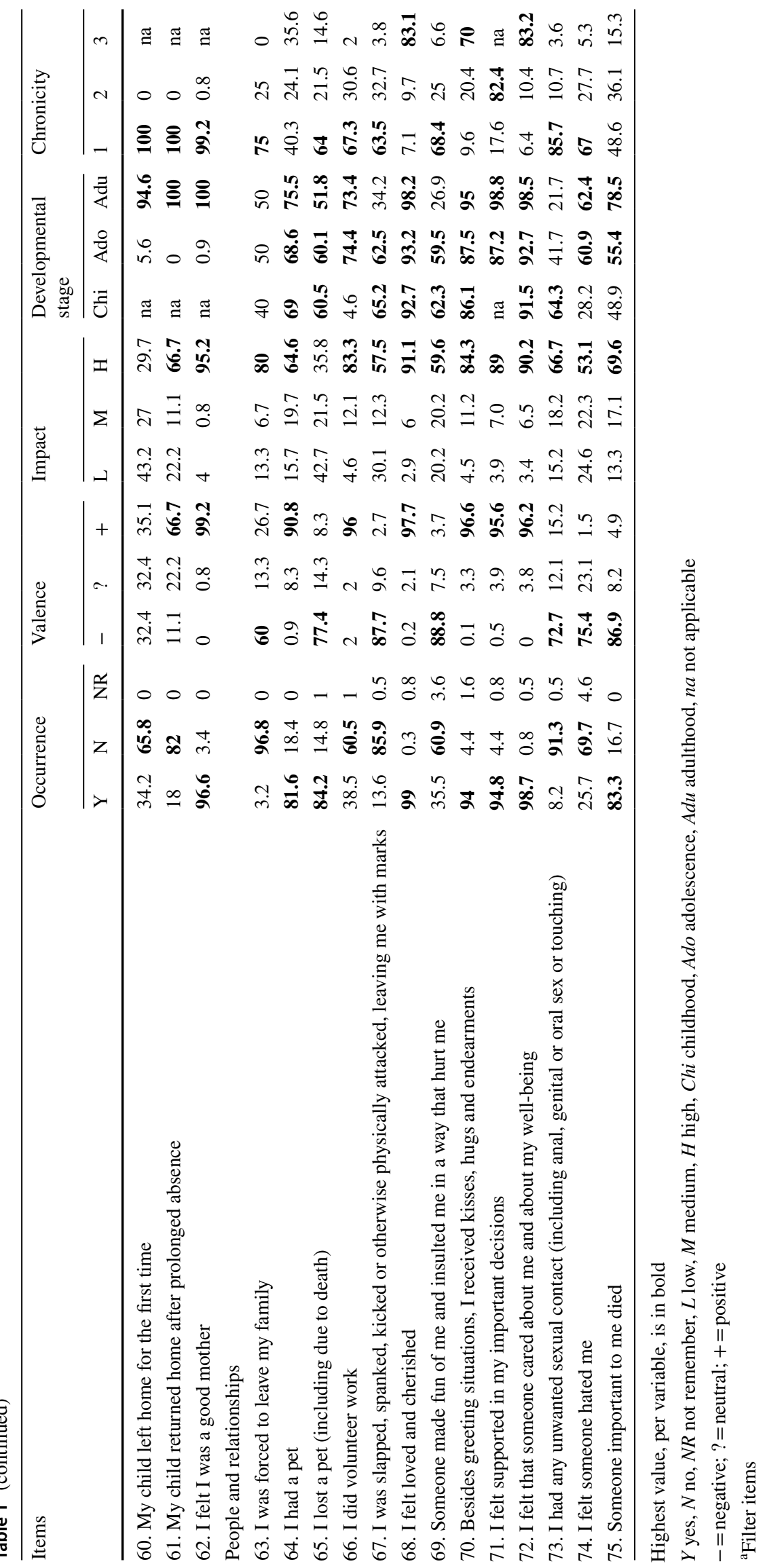


whereas 59 items, belonging to all the domains assessed, were rated by at least $51 \%$ of the participants as high-impact experiences. More specifically, more than $90 \%$ of the participants rated the following experiences as high impact: $I$ experienced pleasure when taking care of my child, I accomplished a project/fulfilled a dream that I really wanted, I felt I was a good motherlfather, I bought/received a vehicle, I got married or lived in cohabitation, I had and recovered from a psychiatric disease, I become economically independent, I felt loved and cherished, I bought/received my own house, I felt that someone cared about me and about my well-being, and I began a professional program or university degree.

\section{Don't Remember}

As seen in Table 1, the I don't remember option represented less than $2 \%$ on 56 of the experiences assessed. Conversely, the items my parents used to exchange words of affection, my parents used to be physically affectionate with each other, and I had leisure time, having fun with myself presented the highest rates of I don't remember answers.

\section{Missingness}

As displayed in Table 2, the majority of life experiences presented a percentage of missings below 5\% (range $0.5-17 \%$ ). Life experiences associated with health showed the highest percentages; additionally, participants tended not to give answers about life experiences associated with school, job, marriage, and children. In contrast, three items included in living conditions and one about leisure presented the lowest values of missings. Moreover, those items involving physical abuse, psychological abuse, and sexual abuse presented very low values of missing answers. When we compared the associated features of the ten items with the highest and the lowest values of missings, there were no marked patterns regarding valence, impact, and chronicity. Inversely, regarding developmental stage, the highest values of missings were associated with life experiences from adulthood, whereas items with fewer missings cannot be included in a single developmental stage.

According to Table 3, participants who were male, aged 41-64 years, married, employed, and had secondary or professional education exhibited a higher percentage of missing variables, cases, and individuals, with a few exceptions (i.e., females had greater missing cases, and participants with the second or third cycle of education presented higher percentages of missing cases and individuals). Although the main core of missing items was shared by all the groups, some missing patterns appeared quite specific: for instance, $I / m y$ partner became pregnant was a common missing when participants were single, students and aged 18-24 years; and $I$ belonged to a sports team was only a critical missing item for those aged 65 or above.

\section{Discussion}

The current study presents some conceptual (i.e., a new definition, new domains) and methodological advances (i.e., answer options available, missingness) in the field of life experience research, which highly compromises comparisons among studies-a difficulty also noted by other authors (e.g., Schroots and Assink 2005; Sobell et al. 1990). Above, we presented independent data for several variables, and this schema will continued to be discussed: for each topic, the main findings will be summarized, discussed and interpreted. Next, the implications and applications of our work will be presented adopting a general perspective. Finally, we will identify and discuss the main limitations of the study, suggesting future directions for research.

\section{Occurrence}

Despite the common trend to rely on very limited time-references, our results are based on a lifetime perspective, which allows covering human life course, and high frequencies of occurrence were consequently reasonable. A pattern in our findings indicated that all the domains included both highand low-frequency experiences, except adverse experiences and accomplishments, which presented only low and high frequencies, respectively. Overall, the participants reported a higher mean value of life experiences than those obtained by Reynolds and Turner (2008). The same authors excluded from their analyses almost a fifth of the participants because they reported no lifetime exposure to any major events, whereas in our sample only one participant did not report any experience. These notable differences can be explained by the conceptual and methodological specificities: whereas we assessed life experiences as both potentially positive and negative and as covering different domains, Reynolds and Turner (2008) included only items labeled as major eventful stressors. Another study was conducted by Hobson and Delunas (2001), which applied a revised version of the SRRS to identify the frequency of life events in the past 12 months. Experiences associated with death were frequently reported by their participants, similarly to ours. In contrast, the same authors concluded that the most frequent experiences concerned work, which was not corroborated in our results. This could be explained by the types of experiences included, since the SRRS included items such as changing work responsibilities, changing employers/careers, employer reorganization/downsizing, or major disagreement with supervisor/co-worker, which were not assessed here. However, there are some similarities between the studies when 
Table 2 Percentage of missing answers by individual items and associated features

\begin{tabular}{|c|c|c|c|c|c|}
\hline Items & Missings & Valence & Impact & Developmental stage & Chronicity \\
\hline \multicolumn{6}{|l|}{ With a percentage of missings higher than 10} \\
\hline I had a serious physical disease/problem & 17 & - & $\mathrm{H}$ & Adu & $\mathrm{U}$ \\
\hline I recovered from a serious physical disease/problem & 17 & + & $\mathrm{H}$ & Adu & $\mathrm{U}$ \\
\hline I recovered from a psychiatric disease & 16 & + & $\mathrm{H}$ & Adu & $\mathrm{U}$ \\
\hline I had a psychiatric disease & 15.2 & - & $\mathrm{H}$ & Adu & $\mathrm{U}$ \\
\hline I finished a professional program or university degree & 14 & + & $\mathrm{H}$ & Adu & $\mathrm{U}$ \\
\hline I had an abortion & 14 & - & und & Adu & $\mathrm{U}$ \\
\hline My child left home for the first time & 14 & und & und & Adu & $\mathrm{U}$ \\
\hline I began a professional program or university degree & 13.2 & + & $\mathrm{H}$ & Ado, Adu & $\mathrm{U}$ \\
\hline My child returned home after prolonged absence & 11.9 & + & $\mathrm{H}$ & Adu & $\mathrm{U}$ \\
\hline I divorced or separated & 11.4 & und & $\mathrm{H}$ & Adu & $\mathrm{U}$ \\
\hline I retired (including due to incapability) & 10.9 & + & $\mathrm{H}$ & Adu & $\mathrm{U}$ \\
\hline \multicolumn{6}{|l|}{ With a percentage of missings between 10 and 5} \\
\hline I changed schools at the same academic level & 9.6 & und & $\mathrm{H}$ & Chi & $\mathrm{U}$ \\
\hline I was expelled from school & 9.6 & - & $\mathrm{L}$ & Ado & $\mathrm{U}$ \\
\hline I became pregnant & 9.4 & + & $\mathrm{H}$ & Adu & $\mathrm{U}$ \\
\hline I got married or lived in cohabitation & 9.1 & + & $\mathrm{H}$ & Adu & $\mathrm{U}$ \\
\hline I was promoted & 8.9 & + & $\mathrm{H}$ & Adu & $\mathrm{U}$ \\
\hline I had a pet & 8.9 & + & $\mathrm{H}$ & Chi, Ado, Adu & $\mathrm{R}$ \\
\hline I abandoned school & 7.9 & und & $\mathrm{H}$ & Ado & $\mathrm{U}$ \\
\hline I became unemployed & 7.9 & - & $\mathrm{H}$ & Adu & $\mathrm{U}$ \\
\hline I experienced pleasure when taking care of my child & 7.1 & + & $\mathrm{H}$ & Adu & $\mathrm{U}$ \\
\hline I lost a pet (including due to death) & 6.9 & - & Und & Chi, Ado, Adu & $\mathrm{U}$ \\
\hline I wished to have a child of a different gender & 6.3 & + & Und & Adu & $\mathrm{U}$ \\
\hline I lived or had contact with my child & 5.3 & na & na & na & na \\
\hline I felt I did not know what to do regarding my child & 5.1 & und & $\mathrm{H}$ & Adu & $\mathrm{U}$ \\
\hline \multicolumn{6}{|l|}{ With a percentage of missings below 5} \\
\hline I felt I was a good mother & 4.8 & + & $\mathrm{H}$ & Adu & $\mathrm{U}$ \\
\hline My child had a serious disease or had severe disability & 4.6 & - & $\mathrm{H}$ & Adu & $\mathrm{U}$ \\
\hline I failed a school year & 4.3 & - & $\mathrm{H}$ & Ado & $\mathrm{U}$ \\
\hline I had a child ${ }^{\mathrm{a}}$ & 4.3 & na & na & na & na \\
\hline I was forced to leave my child & 4.1 & - & $\mathrm{H}$ & Adu & $\mathrm{U}$ \\
\hline I was admitted to a hospital & 3.8 & und & und & Adu & $\mathrm{U}$ \\
\hline I was forced to leave my family & 3.6 & - & $\mathrm{H}$ & und & $\mathrm{U}$ \\
\hline \multicolumn{6}{|l|}{ With a percentage of missings below 5} \\
\hline I accomplished a project/fulfilled a dream that I really wanted & 3 & + & $\mathrm{H}$ & Adu & $\mathrm{U}$ \\
\hline I belonged to a recreational or cultural group & 2.8 & + & $\mathrm{H}$ & Ado, Adu & $\mathrm{U}$ \\
\hline I was involved in an intimate relationship, including dating or marriage ${ }^{\mathrm{a}}$ & 2.8 & na & na & na & na \\
\hline I changed schools due to progress of academic level & 2.5 & + & $\mathrm{H}$ & Chi, Ado & $\mathrm{U}$ \\
\hline $\begin{array}{l}\text { I earned a prize or I was recognized for something that I did (e.g., school, } \\
\text { sport, job) }\end{array}$ & 2.5 & + & $\mathrm{H}$ & Ado, Adu & $\mathrm{U}$ \\
\hline I felt I was contributing to a better world/I am proud of my legacy & 2.5 & + & $\mathrm{H}$ & Ado, Adu & $\mathrm{U}$ \\
\hline I lost my house or my belongings & 2.3 & - & $\mathrm{H}$ & Adu & $\mathrm{U}$ \\
\hline Besides greeting situations, I received kisses, hugs and endearments & 2.3 & + & $\mathrm{H}$ & Chi, Ado, Adu & $\mathrm{R}$ \\
\hline Have some work experience ${ }^{a}$ & 2 & na & na & na & na \\
\hline I had leisure time, having fun with myself & 2 & + & $\mathrm{H}$ & Chi, Ado, Adu & $\mathrm{R}$ \\
\hline I was involved in a crime & 2 & und & $\mathrm{L}$ & Ado & $\mathrm{U}$ \\
\hline I was arrested & 2 & $\mathrm{~b}$ & $\mathrm{~b}$ & $\mathrm{~b}$ & $\mathrm{~b}$ \\
\hline I made a journey or visited a place that I really wanted to see & 2 & + & $\mathrm{H}$ & Adu & $\mathrm{U}$ \\
\hline I felt supported in my important decisions & 2 & + & $\mathrm{H}$ & Ado, Adu & $\mathrm{R}$ \\
\hline
\end{tabular}


Table 2 (continued)

\begin{tabular}{|c|c|c|c|c|c|}
\hline Items & Missings & Valence & Impact & Developmental stage & Chronicity \\
\hline I felt that someone cared about me and about my well-being & 2 & + & $\mathrm{H}$ & Chi, Ado, Adu & $\mathrm{R}$ \\
\hline Most of the time I felt healthy & 1.8 & + & $\mathrm{H}$ & Chi, Ado, Adu & $\mathrm{R}$ \\
\hline I belonged to a sports team & 1.8 & + & $\mathrm{H}$ & Chi, Ado & $\mathrm{U}$ \\
\hline I was involved in a serious accident with a vehicle & 1.8 & - & $\mathrm{H}$ & Adu & $\mathrm{U}$ \\
\hline I was involved in a fire & 1.8 & - & $\mathrm{L}$ & Ado, Adu & $\mathrm{U}$ \\
\hline I was involved in a robbery & 1.8 & - & und & Adu & $\mathrm{U}$ \\
\hline Knew about my parents' relationship ${ }^{a}$ & 1.8 & na & na & na & na \\
\hline I did volunteer work & 1.8 & + & $\mathrm{H}$ & Ado, Adu & $\mathrm{U}$ \\
\hline My parents got divorced & 1.5 & - & $\mathrm{H}$ & und & $\mathrm{U}$ \\
\hline My parents used to shout at each other & 1.5 & - & $\mathrm{H}$ & Chi, Ado, Adu & $\mathrm{R}$ \\
\hline I felt loved and cherished & 1.5 & + & $\mathrm{H}$ & Chi, Ado, Adu & $\mathrm{R}$ \\
\hline I began elementary school $^{\mathrm{a}}$ & 1.3 & na & na & na & na \\
\hline I belonged to a religious group & 1.3 & + & $\mathrm{H}$ & Chi, Ado & und \\
\hline I had leisure time, having fun with my family & 1.3 & + & $\mathrm{H}$ & Chi, Ado, Adu & $\mathrm{R}$ \\
\hline I felt safe in the place where I lived & 1.3 & + & $\mathrm{H}$ & Chi, Ado, Adul & $\mathrm{R}$ \\
\hline I bought/received my own house & 1.3 & + & $\mathrm{H}$ & Adu & $\mathrm{U}$ \\
\hline I bought/received a vehicle & 1.3 & + & $\mathrm{H}$ & Adu & $\mathrm{U}$ \\
\hline My parents used to physically attack each other & 1.3 & - & $\mathrm{H}$ & Chi, Ado & und \\
\hline My parents used to insult each other & 1.3 & - & $\mathrm{H}$ & Chi, Ado, Adu & $\mathrm{R}$ \\
\hline My parents used to be physically affectionate with each other & 1.3 & + & $\mathrm{H}$ & Chi, Ado, Adu & $\mathrm{R}$ \\
\hline $\begin{array}{l}\text { I was slapped, spanked, kicked or otherwise physically attacked, leaving me } \\
\text { with marks }\end{array}$ & 1.3 & - & $\mathrm{H}$ & Chi, Ado & $\mathrm{U}$ \\
\hline Someone made fun of me and insulted me in a way that hurt me & 1.3 & - & $\mathrm{H}$ & Chi, Ado & $\mathrm{U}$ \\
\hline $\begin{array}{l}\text { I had any unwanted sexual contact (including anal, genital or oral sex or } \\
\text { touching) }\end{array}$ & 1.3 & - & $\mathrm{H}$ & Chi & $\mathrm{U}$ \\
\hline I felt someone hated me & 1.3 & - & $\mathrm{H}$ & Ado, Adu & $\mathrm{U}$ \\
\hline My parents used to exchange words of affection & 1 & + & $\mathrm{H}$ & Chi, Ado, Adu & $\mathrm{R}$ \\
\hline Someone important to me died & 1 & - & $\mathrm{H}$ & Ado, Adu & $\mathrm{R}$ \\
\hline The food available for my meals was insufficient & 0.8 & und & $\mathrm{H}$ & Chi, Ado & $\mathrm{R}$ \\
\hline I changed residences & 0.8 & + & $\mathrm{H}$ & Adu & $\mathrm{U}$ \\
\hline I became economically independent & 0.8 & + & $\mathrm{H}$ & Adu & $\mathrm{U}$ \\
\hline I had leisure time, having fun with my friends/colleagues & 0.5 & + & $\mathrm{H}$ & Chi, Ado, Adu & $\mathrm{R}$ \\
\hline
\end{tabular}

$L$ low, $H$ high, $C$ childhood, $A d o$ adolescence, $A d u$ adulthood, $U$ unique, $R$ repetitive, na not applicable, und undefined

$-=$ negative $+=$ positive

${ }^{a}$ Filter items

${ }^{\mathrm{b}}$ Ratings not available

we compare the less frequent experiences, namely legal issues (i.e., being involved in a crime or being arrested), abortion, abuse experiences, or divorce.

In our study, experiences included in people and relationships were the most and the least frequently reported, probably due to the number and type of items assessed in this domain. This type of pattern was also observed by Schroots and Assink (2005), who found that relationships was the modal category in the portraits of their participants, whereas births was the most infrequent.

It is reasonable to suspect that the occurrence of life experiences is highly affected by other variables, such as age or contextual factors. More specifically, due to the reference period covered, i.e., lifetime, a cumulative effect is expected, which probably reflects not only the increasing number of lived experiences but also a diversification (by domain) of the experiences. The relevance of contextual factors was also stressed by Schroots and Assink (2005), who concluded, for instance, that war dominated the childhood experiences of the older participants but not the young or middle groups; in contrast, young participants reported more experiences related to school than the other two groups. Therefore, any result regarding occurrence cannot be disentangled from potential associated variables. 
Table 3 Patterns of missing answers by groups and total

\begin{tabular}{|c|c|c|c|c|}
\hline \multirow[t]{2}{*}{ Groups } & \multicolumn{3}{|c|}{ Percentage of missing } & \multirow{2}{*}{$\begin{array}{l}\text { Top ten of items with the highest } \\
\text { frequency of missings }{ }^{\mathrm{a}}\end{array}$} \\
\hline & Variables & Cases & Individuals & \\
\hline \multicolumn{5}{|l|}{ Gender } \\
\hline Female & 98.7 & 42.2 & 4.7 & $17,18,16,15,5,20,60,4,52,61$ \\
\hline Male & 100 & 36.6 & 5.2 & $18,16,60,17,15,12,10,4,61,20$ \\
\hline \multicolumn{5}{|l|}{ Age (years) } \\
\hline $18-24$ & 56 & 22 & 2 & $51,19,20,52,18,17,16,15,54,53,5$ \\
\hline $25-40$ & 85.3 & 48.7 & 5.3 & $60,17,4,18,16,5,61,15,20,3$ \\
\hline $41-64$ & 100 & 76.8 & 9.3 & $18,17,16,15,12,5,11,8,60,10$ \\
\hline 65 or above & 81.33 & 13.2 & 2.4 & $11,10,58,21,18,4$ \\
\hline \multicolumn{5}{|l|}{ Marital status } \\
\hline Single & 73.3 & 26.4 & 2.6 & $19,20,51,52,18,17,16,15,5,4$ \\
\hline Married & 100 & 65.9 & 8.6 & $17,18,60,16,5,15,4,12,61,8$ \\
\hline Divorced & 32 & 58.8 & 5.2 & $61,60,18,17,16,15,12,3,64,20$ \\
\hline Widowed & 84 & 29.6 & 4.7 & $18,17,15,11,10,8,7,6,4,3$ \\
\hline \multicolumn{5}{|l|}{ Labor force status } \\
\hline Student & 54.7 & 23.0 & 1.9 & $19,51,20,52,18,17,16,15,5$ \\
\hline Employed & 100 & 58.8 & 7.3 & $17,18,16,15,5,60,4,12,20,61$ \\
\hline Unemployed & 48 & 45.8 & 6.9 & $61,60,62,59,58,57,56,55,54,4$ \\
\hline Retired & 84 & 19.1 & 2.6 & $10,16,15,11$ \\
\hline Homemaker & 8 & 0 & 8 & $18,17,16,15,5,4$ \\
\hline \multicolumn{5}{|l|}{ Education } \\
\hline 4 or less years & 81.3 & 17.1 & 2.5 & $18,16,15,11,10,4$ \\
\hline 2nd and 3rd cycle & 94.7 & 63 & 11.4 & $5,4,16,60,20,15,12,17,8,18$ \\
\hline High & 100 & 33.1 & 4.2 & $18,17,60,5,16,15,61,20,4,52$ \\
\hline Graduated & 93.3 & 52.3 & 5 & $18,17,16,15,20,60,8,3,61,52$ \\
\hline Total & 100 & 40.9 & 4.8 & $18,17,16,15,60,20,5,4,61,52$ \\
\hline
\end{tabular}

${ }^{a}$ Items identified through theirs numbers

\section{Development Stage and Chronicity}

Although we assessed lifetime experiences, we also collected data on the developmental stage(s) of occurrence. This strategy allowed us to not only organize experiences by developmental stage but also explore (dis)continuity patterns, i.e., whether the experience was unique or crossed different stages. Globally, the majority of the assessed life experiences seemed to be limited to a particular developmental stage rather than chronic. Such domains as school, leisure, and people and relationships included experiences throughout childhood, adolescence, and adulthood; adverse experiences and accomplishments tended to occur in adolescence and adulthood; and work, health, and living conditions represented experiences mainly lived in adulthood. Schroots and Assink (2005), comparing adults from different age groups, also noted similar patterns; for instance, younger subjects mainly reported experiences involving school and fewer about work and health.

At least partially, our results can also be compared with those from Hobson and Delunas (2001), who assessed the number of incidences of each life event in the past 12 months. According to their results, the lowest numbers of incidents were observed in a constellation of experiences: addressing infertility/miscarriage, pregnancy, divorce, marriage/remarriage, and death of a spouse. In contrast, the number of incidents relating to the death of a close friend or family member was above 1 , corroborating our results that deaths are repetitive experiences.

Once again, the descriptive results presented are neither surprising nor counterintuitive, which does not lessen their usefulness. For instance, although traditionally life experiences are assessed in a dual approach (childhood and adolescence vs. adulthood), our results revealed that adolescence is a bidirectional intermediary that in some cases benefits from being grouped with childhood and in other cases with adulthood. Moreover, the description of common patterns clarifies the potential criteria for the identification of unusual experiences (i.e., an experience occurring in adulthood when it usually occurs in childhood or repetitive experiences that are usually presented as unique). 


\section{Valence}

There was a notable trend of agreement on valence, suggesting that most participants rated each individual item as either negative or positive, which can be seen as evidence in favor of objective or external (i.e., raters) norms. Nevertheless, some exceptions are also notable: for instance, I was admitted to the hospital was rated by $43.1 \%$ as neutral, $39.1 \%$ as negative, and $17.8 \%$ as positive; and I got divorced or separated achieved a tie between positive and negative ratings (39.1\% for each) and was rated as neutral by $21.7 \%$. Traditionally, these items are labeled as negative (e.g., Scully et al. 2000; Voorpostel et al. 2012). Based on these results, the adoption of normative labels-at least for some experiences_can be misleading. Indeed, as Zimmerman (1983, p. 350) argued, "it may be necessary to assess individual perceptions (...), with both the positive and negative feelings taken into account when attempting to understand a person's experience with life events."

Moreover, our results revealed an asymmetry in valence ratings: the majority of life experiences were rated as positive suggesting that the measure applied contradicts the common negative bias in life events assessment (e.g., Baumeister et al. 2001; Zimmerman 1983). Due to the low number of studies including positive experiences, these results are exploratory but not intriguing. Indeed, Schroots and Assink (2005) concluded that overall participants recalled both positive and negative experiences; moreover, middleaged participants reported exclusively positive memories, whereas older adults presented equal numbers of positive and negative memories. Overbeek et al. (2010) separately explored positive and negative experiences and concluded that participants reported a higher number of positive ones; more specifically, $20.4 \%$ of the participants presented three or more life experiences, whereas only $9.5 \%$ reported similar values of negative experiences. Zimmerman (1983) also noted the co-occurrence of both experiences and argued that some negative experiences may precede positive ones and vice-versa (e.g., abortion and pregnancy).

In sum, Baumeister et al. (2001, p. 359) argued that "the lives of American and Western European citizens (from whom the majority of data are collected) are exceptional in the disproportionately high frequency of good events"; nevertheless, meanings of valence may constitute a more complex phenomenon than usually thought. As Overbeek et al. (2010) suggested, valence is not a consensual (i.e., a divorce can be either positive or negative) nor isolated (i.e., the birth of a child after a divorce) appraisal.

\section{Impact}

Globally, life experiences tended to be rated as high-impact, suggesting that the participants perceived their experiences as significant. This pattern is even more evident with experiences associated with people and relationships, which could be evidence of the centrality of personal relationships found by Pilgrim et al. (2009). In line with that result, Reynolds and Turner (2008) concluded that events rated as crises involved mainly experiences of emotional and physical abuse. In an effort to establish updated norms for the SRRS, Hobson and Delunas (2001) provided an index of significance based on frequency and perceived stressfulness. Similarly to our results, they concluded that the most significant life events were associated with family and personal themes. In contrast, only three experiences were rated by most participants as low impact, i.e., I was involved in a fire, I was expelled from school, and I was involved in a crime. School and legal issues also emerged among the less significant experiences in Hobson and Delunas's (2001) study, although they assessed different experiences.

Scully et al. (2000) found that the mean of readjustment ranged from 8 to 58 across almost all the experiences assessed; the only exception was the death of the spouse. When we focused on only the experiences mainly rated as high impact, the percentages of ratings ranged from 51 to 97. These results suggest a remarkable degree of variability among items when such dimensions as impact or readjustment are assessed, which can be interpreted as the distinction between minor and major experiences. Consequently, an unavoidable question arises: should all experiences be treated equally? If the answer is yes, then a simple count of experiences will be sufficient; if the answer is no, then a more complex scoring should be used, which can include normative or subjective ratings. Different scoring options present specific advantages and disadvantages, addressed below; nonetheless, it seems unreasonable to absolutely dismiss this meaning.

\section{Don't Remember}

Typically memory is one of the main challenges in this field of research; paradoxically, it tends to be a side-issue confined to discussion sections, especially on limitations. Traditionally, life experience measures do not allow for ordinary I don't remember responses; moreover, studies about remembering and life events rely mainly on experimental design and free or cued recall. Attending to this state of the art, our results are quite pioneering and informative.

Embedded in the euphoric and skeptical statements about the SRRS, Jenkins et al. (1979) presented an appealing work entitled Life changes: Do people really remember? comparing life change scores provided by 341 males, who were assessed twice over a 9-month period. The authors found that life change scores remained identical in only $26.2 \%$ of the participants and that the majority omitted at the second assessment experiences reported previously. According to 
the researchers, this discrepancy in responses was due to forgetting. A recent study by Langeland et al. (2015) explored memory as a potential reason for inconsistent reporting about childhood sexual abuse. The authors twice assessed 2462 adults, who answered an online questionnaire including questions about demographics, psychiatric symptoms and sexual abuse. Later, in a third assessment, participants were asked to justify their response changes from the first to the second assessments. Langeland et al. (2015) found that memory was not cited as a main reason; I cannot remember was reported by $13.2 \%$ of the participants who changed their responses from yes to no and by $5.3 \%$ of those who changed from no to yes. Differing from these studies in many features, our results seem to favor less pessimistic perspectives regarding memory: indeed, the frequency of I don't remember responses was below $2 \%$ in the majority of the experiences assessed. The type of task performed by our participants may be one explanation of this result, as recognition tasks seem to be less sensitive to forgetting than recall tasks (e.g., Anderson 2009).

In contrast, a major exception was observed in items concerning parents' relationship, especially those experiences involving positive interactions between them, which seems plausible in light of the type of experiences assessed, i.e., witnessed and potential private experiences. In some sense, Dube et al.'s (2004) study corroborated these results: when they compared questions from the Conflict Tactics Scale focused on the self vs. on parents, in two distinct assessments, kappa values of agreement were slightly higher for experiences involving to parents' relationship; however, standard-errors were also higher, suggesting less stable responses.

Taken as a whole, available evidence suggests that memory certainly affects reports of life experiences (e.g., Goodman et al. 2010; Jenkins et al. 1979; Lotterman and Bonanno 2014); however, how much and in what way in cross-sectional retrospective designs remains very unclear. At this point, however, it is clear that the topic encompasses significant complexity and inter-dependency; as Fivush and Shukat (1995, p. 14) argued

to tell a coherent story, one must go beyond reporting what happened (referential information). One also must place the event in context by telling when and where it occurred and who was present (orientation). Most important, one must provide an evaluative framework for understanding the story (evaluation).

\section{Missingness}

Applying Graham's (2009) benchmark, we can conclude that in the majority of life experiences, the number of missing answers was not overwhelming. Moreover, those items that could be considered more sensitive (i.e., involving abuse experiences) achieved low values of missingness. Although this pattern contradicts general opinion, it is not unexpected: as Tourangeau et al. (2009, p. 260) claimed, "the relation between sensitivity and the rate of missing data is not so striking." Remarkably, health experiences seemed to be particularly prone to missingness, which may be inflated by the number of filter items (i.e., health problem/recovery; pregnancy/abortion).

In the absence of clear patterns, valence, impact, and chronicity did not seem to affect missingness; contrariwise, higher values of missingness were observed in life experiences from adulthood, suggesting an influence of developmental stage. Overall, participants who presented higher missing answers tended to be male, aged 41-64, employed, married, and educated. This profile has some similarities (i.e., gender, age) and some differences (i.e., employment status, education) compared to the profile presented by Patel et al. (2003) regarding the main factors adversely affecting unit nonresponse.

These results are noteworthy, since no previous study about life experiences addressed this issue. Full and deep knowledge of reasons for missingness is difficult if not impossible (e.g., Enders and Gottschall 2011; Graham 2009; Schafer and Graham 2002). Because current data rely on a descriptive study of missingness, identification of potential reasons involved is a purely speculative exercise. Being cautious about causal statements, our anecdotal evidence (throughout data collection, data entering, and data analysis) favors a skipping behavior more than a more complex pattern. In light of the evidence available, we cannot strongly endorse missing at random or not at random-a decision that depends largely on the judgment of the researcher (Foster and Krivelyova 2008). To improve the current state of the art, which in turn affects strategies to address missing answers, we support the appeals by other authors (e.g., Schafer and Graham 2002) for more and better research about missingness.

\section{Implications and Applications}

In light of its novelty and findings, the present study contributes to our understanding about the way life experiences are (un)told and their meanings. Although life experiences are traditionally rooted in clinical and health psychology, they are a transversal topic that is equally relevant to other fields of psychology, such as justice or education. Moreover, the results presented here can be useful for both research and clinical purposes. The comprehensiveness and exhaustiveness of our results allowed us to obtain an overall picture of what did or did not occur throughout the lifespan of an individual, contradicting the general trend of focusing on a limited range of experiences while ignoring others. 
Consequently, "gathering sufficient data about the adversity, the person's social circumstances, relationships and major life events may also help investigate the possible role of other variables and process" (Davidson et al. 2010, p. 383).

The best strategy to score life experiences remains a subject of vibrant debate because both options, i.e., subjective and normative, present pros and cons. For instance, Paykel (1983) argued that normative techniques reduce sensitivity, whereas subjective techniques increase proneness to bias. To resolve this debate, it is tempting to rely on the occurrence of specific experiences or on the total count of lived experiences, a strategy widely applied in more recent studies (e.g., ACE Study). Again, these options are not free of criticism, mainly stressing that experiences should not be treated equally and an effort should be made to distinguish them (e.g., Paykel 1983; Reynolds and Turner 2008). Nonetheless, these alternatives are not always mutually exclusive. Indeed, instead of favoring a single approach, we collected data based on a subjective approach (allowing participants to present their meanings); however, the data were analyzed to identify trends, denoting a normative effort. In the same line, proposing a conciliatory solution, Cleary (1980, p. 202) suggested that scoring should include two distinct approaches: "routine use of method 5 [count of event frequency] along with the method which the researcher feels most appropriate would serve as a useful check on the utility of the entire procedure of scaling and weighting events." According to Davis et al. (1999, p. 92), "focus in the past on inter-group than intra-individual comparisons may have obscured meaningful individual differences"; therefore, the increasing work associated with Cleary's proposal will probably be compensated by increased knowledge and understanding about life experiences. The debate about scoring has obvious implications for both clinicians and researchers. According to the idiosyncrasy presented in our results, greater efforts should be made to collect subjective meanings. For instance, when assessing a life experience such as divorce, it is important to not only ask about its occurrence but also collect personal appraisals, which can be compared (or not) with normative labels. Indeed, although $99 \%$ of the individuals may label a specific event as negative, the remaining $1 \%$ is equally important and informative and should not be dismissed (or should, if there are good reasons to do so).

Also associated with implicit meanings, the potential influence of a priori labels is another major implication of this study. As noted by Davidson et al. (2010, p. 378-380)

there are concerns that the claims made from the findings of survey data present a unified picture when in reality the lived experience of individuals will be very different. For example, the notion that some outcomes can be categorized as either 'good' or 'poor' in itself is subjective, and social surveys are often criticized for fitting individuals into predetermined categories rather than allowing individuals to describe their own reality and perception of outcomes.

As a result, when we directly asked the participants about dimensions narrowing the answer options, i.e., we are interested in major or minor/positive or negative life experiences, we could not preclude the results differing from those resulting from neutral directions, i.e., we are interested in life experiences. Therefore, special attention should be paid to all details when life experiences are assessed.

\section{Limitations and Future Studies}

Our study has several limitations, which should be addressed and discussed. First, although the measure applied is quite comprehensive, covering domains that are usually omitted, it is far from complete. Indeed, all measures of life experiences are limited because they cannot cover all the potential items (e.g., Cleary 1980; Paykel 1983; Zimmerman 1983); including blank spaces devoted to other experiences, as we did, seems to be a useful strategy to address this concern.

According to some studies (e.g., Reynolds and Turner 2008; Schroots and Assink 2005; Zimmerman 1983), life experiences are not equally distributed across groups, being affected by variables such as gender, age, and disability status, but not by education or ethnicity. Moreover, based on a meta-analytic approach, Davis et al. (1999) found that differences between males and females are not limited to occurrences but also to appraisals (or meanings), with females reporting more stressful events and rating them as more intense. Our data analysis did not discriminate nor compare groups; the scope of our analysis can be extended in future studies to clarify differences and similarities among groups.

Recodification of some variables can be a third limitation. For instance, the original five-point Likert scale regarding impact was recoded in three categories-low, medium, and high impact. This strategy surely simplified interpretation but also simplified meanings, decreasing the sensitivity of the results. Therefore, a future analysis should be performed favoring more detailed answers. Additionally, this study was merely descriptive, which can be seen as a limitation. Indeed, due to soundness claims about factorial analyses, it is tempting to argue about its relevance for life experiences. Indeed, this effort was made by Hobson and Delunas (2001, p. 306), who concluded that "results were disappointing in terms of providing a parsimonious, meaningful representation of the interrelationships among frequency ratings for the 51 life-event." Therefore, future studies can include more complex statistical analyses (e.g., cluster analysis), taking into account the specificities involved in the life experience construct (e.g., Bollen and Bauldry 2011; Hooper et al. 2011). 
Another controversial issue regarding data analysis can be the criterion used to evaluate majority; indeed, if we replaced the benchmark we applied (51\% or more) with the third quartile (75\%), the conclusions drawn might be affected. Consequently, future studies should address this concern.

Our initial aim was to identify which life experiences were shared by the participants, to understand their meanings, and to identify those that were untold (attending to missingness and I don't remember answers). Obviously, our results are a reflection of the participants assessed, as well as the mode of data collection, which can be a limitation. However, refusals to participate or to answer specific questions are ethical rights that must be respected. Consequently, as Davidson et al. (2010) argued, future studies should pay particular attention to the factors influencing participation and disclosure.

Finally, concerns regarding the reliability or consistency of reports about life experiences also applied to the current study. Despite being an old issue (e.g., Zimmerman 1983), there are still few studies specifically designed to address it; moreover, available evidence focuses mainly on occurrences. Therefore, consistency should be deeply analyzed in further studies, in an effort to include other variables (i.e., valence, impact), to clarify patterns (i.e., under- or over-reporting), and to identify associated features.

In sum, revisiting Paykel's (2001) work entitled The evolution of life events research in psychiatry, the advances and improvements in this field of research are notable; surprisingly, some relevant conceptual, methodological, and empirical issues have remained unchanged for decades. Therefore, despite those limitations, in our opinion, the present study offers several important new insights into this field of interest, such as a new definition of life experiences, comprehensive data on occurrences and meanings across several domains, and empirical clues about memory and missingness. Overall, the evidence collected suggests that life experiences are mainly an idiosyncratic topic.

Funding This manuscript is part of a doctoral dissertation, which had the support of the Portuguese Foundation for Science and Technology (FCT), through the PhD grant with the reference SFRH/ BD/76022/2011, funded by POPH-QREN-Typology 4.1-Advanced Training, reimbursed by the European Social Fund and national funds from State Budget. This study was conducted at Psychology Research Centre (UID/PSI/01662/2013), University of Minho, and supported by the Portuguese Foundation for Science and Technology and the Portuguese Ministry of Education and Science through national funds and co-financed by FEDER through COMPETE2020 under the PT2020 Partnership Agreement (POCI-01-0145-FEDER-007653).

\section{Compliance with Ethical Standards}

Conflict of interest The authors declare that they have no conflict of interest.
Ethical Approval Ethical standards were followed in the conduct of the study.

Informed Consent Written informed consent was obtained from all participants.

\section{References}

Anderson, M. C. (2009). Incidental forgetting. In A. Baddeley, M. W. Eysenck \& M. C. Anderson (Eds.), Memory (pp. 191-216). New York: Psychology Press.

APA Publications and Communications Board; Working Group on Journal Article Reporting. (2008). Reporting standards for research in psychology: Why do we need them? What might they be?. The American Psychologist, 63(9), 839-851. https://doi. org/10.1037/0003-066X.63.9.839.

Azevedo, V., Martins, C., \& Maia, A. (2017). Lifetime Experiences Scale (LIFES): Development, validation, and reliability in community samples. Manuscript submitted for publication.

Baumeister, R. F., Bratslavsky, E., Finkenauer, C., \& Vohs, K. D. (2001). Bad is stronger than good. Review of General Psychology, 5(4), 323-370. https://doi.org/10.1037//1089-2680.5.4.323.

Beckett, M., Da Vanzo, J., Sastry, N., Panis, C., \& Peterson, C. (2001). The quality of retrospective data: An examination of long-term recall in a developing country. Journal of Human Resources, 36(3), 593-625. https://doi.org/10.2307/3069631.

Bollen, K. A., \& Bauldry, S. (2011). Three Cs in measurement models: Causal indicators, composite indicators, and covariates. Psychological Methods, 16(3), 265-284. https://doi.org/10.1037/ a0024448.

Centers for Disease Control and Prevention and Kaiser Permanente Adverse Childhood Experiences (ACE) Study (2016). Adverse childhood experiences. Retrieved from http://www.cdc.gov/violenceprevention/acestudy/index.html. Accessed 1 Mar 2016

Cleary, P. J. (1980). A checklist for life event research. Journal of Psychosomatic Research, 24(3-4), 199-207. https://doi. org/10.1016/0022-3999(80)90042-2.

Davidson, G., Devaney, J., \& Spratt, T. (2010). The impact of adversity in childhood on outcomes in adulthood: Research lessons and limitations. Journal of Social Work, 10(4), 369-390. https://doi. org/10.1177/1468017310378783.

Davis, M. C., Matthews, K. A., \& Twamley, E. W. (1999). Is life more difficult on Mars or Venus? A meta-analytic review of sex differences in major and minor life events. Annals of Behavioral Medicine, 21(1), 83-97. https://doi.org/10.1007/BF02895038.

Dohrenwend, B. P. (2006). Inventoring stress life events as risks factors for psychopathology: Toward resolution of the problem of intracategory variability. Psychological Bulletin, 132(2), 477-495. https://doi.org/10.1037/0033-2909.132.3.477.

Dube, S. R., Williamson, D. F., Thompson, T., Felitti, V. J., \& Anda, R. F. (2004). Assessing the reliability of retrospective reports of adverse childhood experiences among adult HMO members attending a primary care clinic. Child Abuse \& Neglect, 28(7), 729-737. https://doi.org/10.1016/j.chiabu.2003.08.009.

Enders, C. K., \& Gottschall, A. C. (2011). The impact of missing data on the ethical quality of a research study. In A. T. Panter \& S. K. Sterba (Eds.), Handbook of ethics in quantitative methodology (pp. 357-381). New York: Routledge/Taylor \& Francis Group.

Fivush, R., \& Shukat, J. R. (1995). Content, consistency, and coherence of early autobiographical recall. In M. S. Zaragosa, J. R. Graham. G. C. N. Hall, R. Hirschman \& Y. S. Ben-Porath (Eds.), Memory and testimony in the child witness (pp. 5-23). Thousand Oaks: Sage Publications. 
Foster, E. M., \& Krivelyova, A. (2008). Nonignorable nonresponse in longitudinal studies. In S. Menard (Ed.), Handbook of longitudinal research: Design, measurement, and analysis (pp. 185-196). London: Academic Press.

Goodman, G. S., Quas, J. A., \& Ogle, C. M. (2010). Child maltreatment and memory. Annual Review of Psychology, 61, 325-351. https:// doi.org/10.1146/annurev.psych.093008.100403.

Graham, J. W. (2009). Missing data analysis: Making it work in the real world. Annual Review of Psychology, 60(1), 549-576. https://doi. org/10.1146/annurev.psych.58.110405.085530.

Grotpeter, J. K. (2008). Respondent recall. In S. Menard (Ed.), Handbook of longitudinal research: Design, measurement, and analysis (pp. 109-138). London: Academic Press.

Hardt, J., \& Rutter, M. (2004). Validity of adult retrospective reports of adverse childhood experiences: Review of the evidence. Journal of Child Psychology and Psychiatry, 45(2), 260-273. https://doi. org/10.1111/j.1469-7610.2004.00218.x.

Hobson, C. J., \& Delunas, L. (2001). National norms and life-event frequencies for the revised social readjustment rating scale. International Journal of Stress Management, 8(4), 299-314. https:// doi.org/10.1023/A:1017565632657.

Holmes, T. H., \& Rahe, R. H. (1967). The social readjustment rating scale. Journal of Psychosomatic Research, 11(5), 213-218. https://doi.org/10.1016/0022-3999(67)90010-4.

Hooper, L. M., Stockton, P., Krupnick, J. L., \& Green, B. L. (2011). Development, use and psychometric properties of the trauma history questionnaire. Journal of Loss and Trauma, 16, 258-283. https://doi.org/10.1080/15325024.2011.572035.

Jenkins, C. D., Hurst, M. W., \& Rose, R. M. (1979). Life changes: Do people really remember? Archives of General Psychiatry, 36(4), 379-384. https://doi.org/10.1001/archp syc. 1979.01780040021001

Kendall-Tackett, K., \& Becker-Blease, K. (2004). The importance of retrospective findings in child maltreatment research. Child Abuse and Neglect, 28(7), 723-727. https://doi.org/10.1016/j. chiabu.2004.02.002.

Langeland, W., Smit, J. H., Merckelbach, H., de Vries, G., Hoogendoorn, A. W., \& Draijer, N. (2015). Inconsistent retrospective self-reports of childhood sexual abuse and their correlates in the general population. Social Psychiatry and Psychiatric Epidemiology, 50(4), 603-612. https://doi.org/10.1007/s00127-014-0986-x.

Lotterman, J. H., \& Bonanno, G. A. (2014). Those were the days: Memory bias for the frequency of positive events, depression, and self-enhancement. Memory, 22(8), 925-936. https://doi.org/10.1 080/09658211.2013.856924.

McAdams, D. P. (2001). The person: An integrated introduction to personality psychology. Orlando: Harcourt College Publishers.

Overbeek, G., Vermulst, A., de Graaf, R., ten Have, M., Engels, R., \& Scholte, R. (2010). Positive life events and mood disorders: Longitudinal evidence for an erratic lifecourse hypothesis. Journal of Psychiatric Research, 44(15), 1095-1100. https://doi. org/10.1016/j.jpsychires.2010.03.019.

Patel, M. X., Doku, V., \& Tennakoon, L. (2003). Challenges in recruitment of research participants. Advances in Psychiatric Treatment, 9(3), 229-238. https://doi.org/10.1192/apt.9.3.229.
Paykel, E. S. (1983). Methodological aspects of life events research. Journal of Psychosomatic Research, 27(5), 341-352. https://doi. org/10.1016/0022-3999(83)90065-X.

Paykel, E. S. (2001). The evolution of life events research in psychiatry. Journal of Affective Disorders, 62(3), 141-149. https://doi. org/10.1016/S0165-0327(00)00174-9.

Pilgrim, D., Rogers, A., \& Bentall, R. (2009). The centrality of personal relationships in the creation and amelioration of mental health problems: The current interdisciplinary case. Health, 13(2), 235-254. https://doi.org/10.1177/1363459308099686.

Reynolds, J. R., \& Turner, R. J. A. Y. (2008). Major life events: Their personal meaning, resolution, and mental health significance. Journal of Health and Social Behavior, 49(2), 223-237. https:// doi.org/10.1177/002214650804900208.

Sarason, I. G., Johnson, J. H., \& Siegel, J. M. (1978). Assessing the impact of life changes: Development of the life experiences survey. Journal of Consulting and Clinical Psychology, 46(5), 932 946. https://doi.org/10.1037/0022-006X.46.5.932.

Schafer, J. L., \& Graham, J. W. (2002). Missing data: Our view of the state of the art. Psychological Methods, 7(2), 147-177. https://doi. org/10.1037//1082-989X.7.2.147.

Schroots, J. J. F., \& Assink, M. H. J. (2005). Portraits of life: Patterns of events over the lifespan. Journal of Adult Development, 12(4), 183-198. https://doi.org/10.1007/s10804-005-7086-9.

Scully, J. A., Tosi, H., \& Banning, K. (2000). Life event checklists: Revisiting the social readjustment rating scale after 30 years. Educational and Psychological Measurement, 60(6), 864-876. https:// doi.org/10.1177/00131640021970952.

Shaffer, A., Huston, L., \& Egeland, B. (2008). Identification of child maltreatment using prospective and self-report methodologies: A comparison of maltreatment incidence and relation to later psychopathology. Child Abuse and Neglect, 32(7), 682-692. https:// doi.org/10.1016/j.chiabu.2007.09.010.

Sobell, L. C., Toneatto, T., Sobell, M. B., Schuller, R., \& Maxwell, M. (1990). A procedure for reducing errors in reports of life events. Journal of Psychosomatic Research, 34(2), 163-170. https://doi. org/10.1016/0022-3999(90)90050-E.

Suh, E., Diener, E., \& Fujita, F. (1996). Events and subjective well-being: Only recent events matter. Journal of Personality and Social Psychology, 70(5), 1091-1102. https://doi. org/10.1037/0022-3514.70.5.1091.

Tourangeau, R., Rips, L. J., \& Rasincki, K. (2009). The psychology of survey response. New York: Cambridge University Press.

Voorpostel, M., van der Lippe, T., \& Flap, H. (2012). For better or worse: Negative life events and sibling relationships. International Sociology, 27(3), 330-348. https://doi. org/10.1177/0268580911423051.

Zimmerman, M. (1983). Methodological issues in the assessment of life events: A review of issues and research. Clinical Psychology Review, 3(3), 339-370. https://doi. org/10.1016/0272-7358(83)90019-3. 